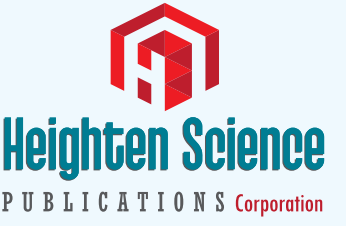

ISSN

2639-9911
*Address for Correspondence: Dr. Hani Ayyash, PhD, MMedSci, MBBS, PGDip Ch Psychiatry, FRCPCH, Consultant Neurodevelopmental Paediatrician, Cambridgeshire and Peterborough NHS Foundation Trust, Chairman, Academic Committee, GSF National Paediatric ADHD Interest Group, RCPCH; Email:

hani.ayyash@cpft.nhs.uk

Submitted: 01 December 2016

Approved: 25 January 2017

Published: 27 January 2017

Copyright: @ 2017 Ayyash H, et al. This is an open access article distributed under the Creative Commons Attribution License, which permits unrestricted use, distribution, and reproduction in any medium, provided the original work is properly cited

Keywords: Psychoeducation; Childhood ADHD; Parenting programme; Non-pharmacological management

Acknowledgements: The authors are extremely grateful to all the parents who participated in the courses. The immense support of Dr Samuel Cortese is hereby acknowledged. He kindly reviewed the draft article and offered helpful comments and encouragement

Check for updates

\title{
The Outcome of an ADHD Parenting Group Training Programme (APEG) In the Peterborough Neurodevelopmental Service (NDS)
}

\author{
Hani Ayyash ${ }^{1 *}$, Michael 0 Ogundele ${ }^{2}$, Ruth Wisbey ${ }^{1}$, Emma \\ Weisblatt ${ }^{1}$, Lorraine Cuff ${ }^{1}$ and Venkat Reddy ${ }^{1}$ \\ ${ }^{1}$ Cambridgeshire and Peterborough NHS Foundation Trust, University of Cambridge Teaching \\ Trust, England \\ ${ }^{2}$ Community Paediatrics Dept, Glenwood Health Centre, NHS Fife, Glenrothes, Scotland
}

\section{SUMMARY}

ADHD is the most common neurodevelopmental disorder in children and adolescents with prevalence ranging between $5 \%$ and $12 \%$ in developed countries. There is ample evidence that carefully structured enhanced behavioural parenting programmes are useful in the management of ADHD.

We assessed the outcome of an ADHD group parenting training programme (APEG) offered between 2014 and 2015 by the Peterborough Neurodevelopmental Service (NDS) in improving the knowledge and skills of carers using a pre-/post-training intervention study.

APEG follows a Parent Advisor Model, consisting of a 6-session programme of evidence-based parenting training.

A total of 27 parents completed the 53 pre- and post-course questionnaires. The knowledge and understanding of the parents increased significantly about all aspects of ADHD diagnosis and management in response to all the 5 questions. The difference between the scores of 0 to 3 and 4 or 5 pre- and postintervention was statistically significant (chi square 239 , $\mathrm{df} 1$, p value $<0.01$ ).

The study suggests that provision of a psychosocial intervention programme for parents of ADHD children through the APEG parenting training proved to be effective in significantly improving the level of knowledge and understanding of parents regarding several aspects of ADHD diagnosis, symptom identification and behaviour control.

\section{INTRODUCTION}

ADHD is the most common neurodevelopmental disorder in children and adolescents with prevalence ranging between $5 \%$ and $12 \%$ in developed countries [1]. ADHD is defined by a persistent ( $>6$ months), age-inappropriate and impairing pattern of inattention and/or hyperactivity/impulsivity. Three main presentations of ADHD as defined by the recently published Diagnostic and Statistical Manual of Mental Disorders, fifth edition (DSM-5) by the American Psychiatric Association [2] are "predominantly inattentive"; "predominantly hyperactive/impulsive"; and "combined". Hyperkinetic Disorder (HKD), defined in the International Classification of Diseases, $10^{\text {th }}$ Edition [3], is a narrower diagnostic category, requiring both symptoms of inattention and hyperactivity/impulsivity overlapping with the "combined presentation" of ADHD as per DSM-5. 
ADHD is thought to be caused by a complex interplay of genetic and environmental factors. There is evidence from published literature that alterations in any single neurotransmitter system are unlikely to explain the complexity of ADHD; rather, the disorder has been linked to dysfunctions in several systems, including the dopaminergic, adrenergic, serotoninergic and cholinergic pathways [4].

ADHD is often comorbid with other psychiatric conditions, such as oppositional defiant disorder/conduct disorder, specific learning disorders, mood and anxiety disorders, and sleep disturbances [5]. Impairing symptoms of ADHD persist in adulthood in up to $65 \%$ of cases [6], with a pooled prevalence of adulthood ADHD calculated at $2.5 \%[7]$.

Because of both core symptoms and comorbid disorders, ADHD imposes an enormous burden on society in terms of psychological dysfunction, adverse vocational outcomes, stress on families, and societal financial costs. In particular, children with ADHD might experience one or more of the following: underachievement at school, problems with family, peer and adult relationships, problems with finding and keeping a job, alcohol and substance abuse and criminal behaviour. Behavioural symptoms in children with neurodevelopmental disorders have been found to be the primary source of parenting stress [8].

There is ample evidence that carefully structured enhanced behavioural parenting programmes are useful in the management of ADHD [1,9]. The National Institute for Health and Care Excellence (NICE) in the UK, recommended that parent training /education programmes should be offered as first-line therapy for children with moderate levels of impairment from ADHD. Medication is offered as first-line treatment in children with severe ADHD, along with a comprehensive treatment plan that includes psychological, behavioural and educational advice. Behavioural interventions might include family therapy focusing on strategies for the family as a whole, and individual therapy focusing on changing behaviours [1].

Previous studies have confirmed the effectiveness of behavior modification for children with ADHD [10]. Recent meta-analyses by the European ADHD Guidelines Group [11,12] have challenged the effectiveness of parent training for ADHD core symptoms, although they clearly show that parent training is useful to decrease ADHD-related impairment and improve parenting skills. Parenting a child with ADHD can lead to increased stress especially when social support is lacking [13,14]. A more recent systematic review of 12 meta-analyses of non-pharmacological psychosocial treatments for ADHD has found considerable diversity across the meta-analyses in terms of the inclusion/exclusion criteria, types of psychosocial treatments reviewed, methodological characteristics, and magnitude of reported effect sizes, making it difficult to aggregate findings across meta-analyses or to investigate moderators of outcome. The published effect sizes varied across various outcomes assessed [15].

The Peterborough Neurodevelopmental Service (NDS) is an integrated multidisciplinary service for school age children and young people with known or suspected neurodevelopmental difficulties. It provides a range of services to children and families including consultation, assessment, diagnosis, interventions, monitoring, review and training. The ADHD Parenting Group (APEG) is a programme designed for support and training of families who have children with ADHD, which follows a Parent Advisor Model, building on the existing knowledge and experience of parents. Experienced trainers follow the core parent programme in 6 sessions focusing on understanding different aspects of ADHD behavior and sensory needs (Appendix 1). The intervention is aimed at improving parents' knowledge of ADHD, building their skills in effective parenting, stress management and problem-solving, as well as providing social support.

This study aimed to identify the outcome of an ADHD group parenting training 
programme offered by the Peterborough Neurodevelopmental Service (NDS) in improving the knowledge and skills of carers.

\section{METHODS}

Parents of children who had received a diagnosis of ADHD within the Neurodevelopmental Service in Peterborough are invited to attend the APEG course. As part of the APEG programme, each parentattending the course was given a questionnaire asking them to rate their knowledge and understanding of 5 different aspects of ADHD in their children: 1) Understanding of local ADHD services; 2) Understanding diagnosis of ADHD; 3) Understanding ADHD medications; 4) Understanding sensory integration and its relevance to a child with ADHD; 5) Understanding of behaviour strategies to manage ADHD (Appendix 2).

The parents and carers rated their confidence in each area on a 6 point scale ranging from 0 (not at all) to 5 (very much). Parents rated the 5 items before starting the course, and following the completion of the 6 core sessions. The parents also had an opportunity to make additional comments in free text. The mean pre-course and a post-course confidence levels for each of five different aspects of ADHD diagnosis and management were compared. Paired Student's t-test was also used to compare the change in mean score between the pre- and post-course responses for each of the five aspects. The responses were also split into "insufficient understanding" (ratings 0-3) and "sufficient understanding" (ratings 4-5) and analysis of the categorical data undertaken using chi-square to compare categories before and after the APEG intervention.

\section{RESULTS}

Peterborough is a city in the Eastern Region of England that has a high level of social deprivation and has also seen a large increase in its population in the last few years. Peterborough City Council Statistics for 2012 recorded a population of 186,400 with the number of children under 5 at 14,700 and 5 to 19 years at 34,600, with 3,300 live births per year. The rates of childhood poverty which is up to $35 \%$ are significantly higher than the rest of the UK where the average is $21.4 \%$.

All children aged between 6 years and 18 years in Peterbrough city are referred to the NDS for concerns about behavior or developmental. They are assessed by a multi-disciplinary team including Paediatricians, Psychiatrists, Psychologist and Developmental Neuropsychiatrists using a number of different screening tools. We receive on average twelve referrals to the NDS every month, out of which an average of 8 children are diagnosed with ADHD. Most of the patients have a range of co-mordities, most commonly Autism (ASD), Oppositional defiant disorder (ODD), Learning difficulties, Anxiety and Conduct disorder. Parents of every newly diagnosed patients are offered the invitation to attend the group parenting programme. From longstanding experience and from unpublished data, the socio-economic and educational background of parents attending the APEG are not significantly different from the parents who have not previously attended. While some parents are keen to attend the APEG within a few months of their children being diagnosed with ADHD, others tend to take a more relaxed attitude, and attend when they are able to arrange a convenient time.

A total of 27 parents taking part in three different 6-session training courses completed the 53 pre- and post-course questionnaires between Jan 2013 and Nov 2014. The total number of ratings for 0 (not at all), 1 (just little), 2 (just enough) and 3 (a bit more) was significantly decreased after the course (22 vs 198) while there was corresponding significantly increased scoring of 4 (more than little) and 5 (very much so) (243 vs 68) (Table 1 ). This difference was highly statistically significant (chi square 
Table 1: Comparison of the parents' total scores before and after the training for all questions.

\begin{tabular}{|l|c|c|}
\hline & Pre & Post \\
\hline Little or no understanding (0-3) & 198 & 22 \\
\hline Much understanding (4-5) & 68 & 243 \\
\hline Chi Square & \multicolumn{2}{|c|}{239.272} \\
\hline p value & \multicolumn{2}{|c|}{$<0.01$} \\
\hline
\end{tabular}

239 , df $1, \mathrm{p}$ value $<0.01)$. There was statistically significant improvement in the selfreported knowledge among the participating care-givers for each of the five aspects assessed when the mean pre- and post-course responses were compared (Table 2). These remain highly significant even allowing for multiple testing, as all $p$ values were less than 0.0001 .

Many parents also made several favourable comments about the training programme and most of them would recommend it to other parents

\section{DISCUSSION}

The results of this study support the notion that evidence-based group Parent training programmes are effective in improving the carers' knowledge and skills in managing their children's ADHD symptoms. A recent review of the literature suggests that Parent training is the most appropriate intervention for preschoolers and for school-age children with mild to moderate impairments from ADHD [16]. The results presented here are similar to those found in a recent study analysing the effectiveness of a post-diagnosis training group for parents of children with ADHD in South Durham of UK [17].

Parent training groups are based on social learning theory and have been found to be effective in reducing oppositional behaviour in children with ADHD and improve parental confidence through empowerment to break coercive behavioural cycles $[1,18]$. Effective training programmes help to increase the parents' knowledge about ADHD and improve their confidence in its management. It also helps to improve adherence to further treatment and provides an opportunity for social support through interaction with active interaction with other parents [19]. The effect of parental psychoeducation on persistence of medication use is however inconsistent [20].

The results of this study should be interpreted with caution because of the inherent limitations. The parents attending the training programme were selected on the basis of voluntary response to invitation to all parents of children newly diagnosed with ADHD. The rate of response was relatively high (on average 75\%), and they may represent a self-selected group of more motivated parents than those who have not accepted the invitation. We did not attempt to evaluate the parents for any symptoms of ADHD in themselves. Parents at risk for ADHD have been shown to have difficulty maintaining effects of multimodal family interventions for themselves and their children [21] which might potentially impact on long-term effects of the group. The study did not set out to be a controlled trial but was an open study of perceived effectiveness by the

Table 2: Comparison of the parents' responses before and after the training for each question (paired t-test).

\begin{tabular}{|l|l|l|l|l|}
\hline Question & Pre Mean (SD) & Post Mean (SD) & Mean of Difference (SD) & P values \\
\hline Understanding of ADHD service & $2.0(1.6)$ & $4.4(0.6)$ & $2.4(1.6)$ & $<0.0001$ * \\
\hline Understanding diagnosis of ADHD & $3.0(1.3)$ & $4.6(0.5)$ & $1.5(1.5)$ & $<0.0001$ * \\
\hline ADHD medications & $2.7(1.4)$ & $4.4(0.9)$ & $1.7(1.6)$ & $<0.0001$ * \\
\hline $\begin{array}{l}\text { Sensory integration and its } \\
\text { relevance to ADHD }\end{array}$ & $2.2(1.6)$ & $4.6(0.6)$ & $2.4(1.7)$ & $<0.0001$ * \\
\hline $\begin{array}{l}\text { Understanding of behaviour } \\
\text { strategies }\end{array}$ & $2.3(1.2)$ & $4.4(0.8)$ & $2.1(1.3)$ & $<0.0001$ *
\end{tabular}


parents undertaking it. This study did not include any measures of symptom change in the children themselves.

The questionnaire used for this study was designed primarily for the evaluation of this training group and has not been validated in any previous large-scale study, although it follows the accepted form of an ordinal 6 point scale. This study has not evaluated the long-term effect of the training programme and further studies are needed to determine if the efficacy of the training persist over a longer-term period. Effects of parental psychoeducation on several domains have been found to persist till at least a year after the intervention [22]. Further work could include analysing concordance of responses between members of the same child's family attending the group, and analysing any correlations between child characteristics (age, comorbidity) and the effectiveness of the group.

\section{CONCLUSION}

Provision of a psychosocial intervention group programme for parents of ADHD children through the APEG parenting training proved to be effective in significantly improving the level of knowledge and understanding of parents regarding several aspects of ADHD diagnosis, symptom identification and behaviour control. Group as opposed to 1:1 interventions have clear health economic benefits and in addition the interaction with other parents is often much appreciated and found beneficial. For parents unable to use group interventions for whatever reason (such as psychiatric illness or life-limiting illness) the sessions can be provided in a 1:1 format.

\section{REFERENCES}

1. National Institute for Health and Care Excellence (NICE): Attention deficit hyperactivity disorder Clinical Guideline CG72. 2008. Ref.: http://www.nice.org.uk/CG72

2. American Psychiatric Association. Diagnostic and Statistical Manual of Mental Disorders. Fifth Edition. DSM-5. American Psychiatric Publishing ed. 2013.

3. WHO. The ICD-10 classification of mental and behavioral disorders: clinical descriptions and diagnostic guidelines 1992; Diagnostic criteria for research. 1993; Geneva.

4. Cortese S. The neurobiology and genetics of Attention-Deficit/Hyperactivity Disorder (ADHD): what every clinician should know. Eur J Paediatr Neurol. 2012; 16: 422-433. Ref.: https://goo.gl/ogtSTF

5. Biederman J, Faraone SV. Attention-deficit hyperactivity disorder. Lancet 2005; 366: 237-248. Ref.: https://goo.gl/ur4ttp

6. Faraone SV, Biederman J, Mick E. The age-dependent decline of attention deficit hyperactivity disorder: a meta-analysis of follow-up studies. Psychol Med. 2006; 36: 159-165. Ref.: https://goo.gl/idQrvS

7. Simon V, Czobor $P$, Balint S, Meszaros A, Bitter I. Prevalence and correlates of adult attention-deficit hyperactivity disorder: meta-analysis. Br J Psychiatry. 2009; 194: 204-211. Ref.: https://goo.gl/e6QhQN

8. Whitney RV, Smith G. Emotional Disclosure through Journal Writing: Telehealth Intervention for Maternal Stress and Mother-Child Relationships. J Autism Dev Disord. 2015; 45: 3735-3745. Ref.: https://goo.gl/IEyicZ

9. Aghebati A, Gharraee B, Hakim Shoshtari M, Gohari MR. Triple p-positive parenting program for mothers of ADHD children. Iran J Psychiatry Behav Sci. 2014; 8: 59-65. Ref.: https://goo.gl/KpDSfi

10. Fabiano GA, Pelham WE Jr, Coles EK, Gnagy EM, Chronis-Tuscano A, et al. A meta-analysis of behavioral treatments for attention-deficit/hyperactivity disorder. Clin Psychol Rev. 2009; 29: 129140. Ref.: https://goo.gl/EcVORT

11. Daley D, Van der Oord S, Ferrin M, Danckaerts M, Doepfner M, et al. European ADHD Guidelines Group. Behavioral interventions in attention-deficit/hyperactivity disorder: a meta-analysis of randomized controlled trials across multiple outcome domains. J Am Acad Child Adolesc Psychiatry. 2014; 53 : 835-847. Ref.: https://goo.gl/OYWpi8

12. Sonuga-Barke EJ, Brandeis D, Cortese S, Daley D, Ferrin M, et al. European ADHD Guidelines Group. Nonpharmacological interventions for ADHD: systematic review and meta-analyses of randomized 
controlled trials of dietary and psychological treatments. Am J Psychiatry. 2013; 170: 275-289. Ref.: https://goo.gl/PK2knU

13. Hinojosa MS, Hinojosa R, Fernandez-Baca D, Knapp C, Thompson LA. Parental strain, parental health and community characteristics among children with attention deficit hyperavtivity disorder. Acad Pediatr. 2012; 12: 502-508. Ref.: https://goo.gl/keTRLj

14. Theule J, Wiener J, Tannock R, Jenkins J M. Parenting stress in families of children with ADHD: a meta-analysis. J Emot Behav Disord. 2013; 21: 3-17.

15. Fabiano GA, Schatz NK, Aloe AM, Chacko A, Chronis-Tuscano A. A systematic review of metaanalyses of psychosocial treatment for attention-deficit/hyperactivity disorder. Clin Child Fam Psychol Rev. 2015; 18: 77-97. Ref.: https://goo.gl/SjnRqg

16. Young S, Amarasinghe JM. Practitioner Review: Non-pharmacological treatments for ADHD: A lifespan approach. J Child Psychol Psychiatry. 2010; 51: 116-133. Ref.: https://goo.gl/MSQ7el

17. Denton R, Lievesley A, Cook E, Htin HK, Atkinson E. Evaluation of a post-diagnosis ADHD parenting programme. ADHD in Practice. 2015; 7: 4-7.

18. Jones K, Daley D, Hutchings J, Bywater T, Eames C. Efficacy of the incredible years basic parent training programme as an early intervention for children with conduct problems and ADHD. Child Care Health Dev. 2007; 33: 749-75. Ref.: https://goo.gl/5wKXLI

19. Montoya A, Colom F, Ferrin M. Is psychoeducation for parents and teachers of children with ADHD efficacious? A systematic literature review. Eur Psychiatry. 2011; 26:166-175. Ref.: https://goo.gl/wZEhe0

20. Montoya A, Hervás A, Fuentes J, Cardo E, Polavieja P, et al. Cluster-randomized. Controlled 12-month trial to evaluate the effect of a parental psychoeducation program on medication persistence in children with attention-deficit/hyperactivity disorder. Neuropsychiatr Dis Treat. 2014; 10: 10811092. Ref.: https://goo.gl/nSAvmj

21. Dawson AE, Wymbs BT, Marshall SA, Mautone JA, Power TJ. The Role of Parental ADHD in Sustaining the Effects of a Family-School Intervention for ADHD. J Clin Child Adolesc Psychol. 2016; 45: 305-319. Ref.: https://goo.gl/OS4ss4

22. Ferrin M, Moreno-Granados JM, Salcedo-Marin MD, Ruiz-Veguilla M, Perez-Ayala V, et al. Evaluation of a psychoeducation programme for parents of children and adolescents with ADHD: immediate and long-term effects using a blind randomized controlled trial. Eur Child Adolesc Psychiatry. 2014; 23: 637-647. Ref.: https://goo.gl/NUqkmd

\section{APPENDIX 1:}

\section{The content and structure of APEG Sessions}

1. What is ADHD and how we diagnose it within our service

2. Sensory information

3. Information on School strategies

4. Home strategies

5. Sleep

6. ADHD medication

\section{APPENDIX 2:}

\section{Pre (Post) Questionnaires *}

Name:

On a scale of 0 to 5 :

0 being "Not at All" and 5 being "Very Much so", please rate the following statement about your personal and family experience (Please circle the appropriate number): 
1. I have an understanding of what the ADHD service in Peterbrough offers.

$\begin{array}{lllll}0 & 1 & 2 & 3 & 4\end{array}$

2. I have an understanding of my child's ADHD diagnosis

$\begin{array}{lllll}0 & 1 & 2 & 3 & 4\end{array}$

3. I have an understanding about the medication used in the treatment of ADHD symptoms

$\begin{array}{lllll}0 & 1 & 2 & 3 & 4\end{array}$ 5

4. I have an understanding of Sensory Integration and the relevance of this to my child's ADHD diagnosis

$\begin{array}{lllll}0 & 1 & 2 & 3 & 4\end{array}$ 5

5. I have an understanding of strategies I can use at home and to suggest to my child's school

$\begin{array}{lllll}0 & 1 & 2 & 3 & 4\end{array}$ 5

6. I have an understanding of how I can positively communicate with my child's school

$\begin{array}{llllll}0 & 1 & 2 & 3 & 4 & 5\end{array}$

7. How useful I find the course

$\begin{array}{lllll}0 & 1 & 2 & 3 & 4\end{array}$ 5

8. Please provide suggestions on how we could improve the course.

* Questions 6 to 8 not part of the pre-Questionnaire 